\title{
Çocuklarda Tamamlayıcı ve Alternatif Tedavi Kullanımı ve Ebeveyn Bilgilerinin Değerlendirilmesi
}

\author{
Duygu AKÇAY*, Ayla YILDIRIMLAR**
}

\section{Çocuklarda Tamamlayıcı ve Alternatif Tedavi Kullanımı ve} Ebeveyn Bilgilerinin Değerlendirilmesi

\begin{abstract}
Amaç: Araştırmada; kronik hastalı̆̆ olmayan çocuklarda tamamlayıcl ve alternatif tedavilerin kullanım ve ebeveyn bilgilerinin değerlendirilmesi amaçlanmıştır.

Gereç ve Yöntem: Araştırma, 16.05.2016 ile 27.05.2016 tarihleri arasında tanımlayıcı tipte yapılmıştır. Araştırmanın evrenini, Antalya Devlet Hastanesi Hüseyin Savaş Semt Polikliniği Çocuk Sa ̆̆lı̆̆l ve Hastalıkları bölümüne başvuru yapan kronik bir hastallğı olmayan çocukların ebeveynleri $(n=696)$ oluşturmuştur. Bu grup içinde çalışmaya gönüllü olarak katılan toplam 125 ebeveynden konuya ilișkin veri toplanmıștır. Araștırma verilerinin toplanmasında konu ile ilgili literatür taranarak araştırmacılar tarafindan olușturulan, ailelerin tanımlayıcı özellikleri ve araştırma konusu ile ilgili sorulardan oluşan bir form kullanılmıştır.
\end{abstract}

Bulgular: Görüsülen ebeveynlerin \%97,6'sl anne olup, $\% 63,2$ 'si 35-44 yaş arasindadır. Ailelerin \%51,2'si destek, $\% 38,4$ 'ü rahatlama amaçlı çocuğu için tamamlayıcı ve alternatif tedavi (TAT) kullandı ğını bildirmiştir. Ailelerin tamamı çocuğ u için TAT türlerinden en az birini kullandı̆̆ını, kullan-

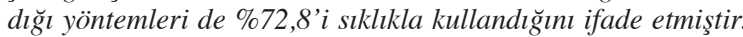
TAT kullanırken \%56'sının çocuğunda herhangi bir yarar, \%97.6'sının zarar gözlemlemediği tespit edilmiştir. Ailelerin

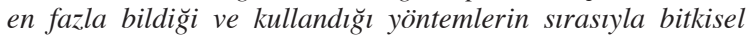
tedavi ile dini yöntem olduğu saptanmıştır. Ekonomik durumlarını orta ve yüksek seviyede (sirasıyla \%71,9, \%94,4) oldu-

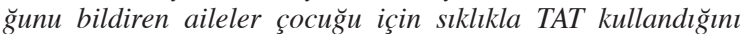
bildirmiştir. Ebeveynlerin eğitim durumu, yaş aralı̆̆ ile çocu$\breve{g u}$ için TAT kullanım siklı̆̆ arasında istatistiksel olarak bir fark bulunamamıştır.

Sonuç: Araştırma grubumuzun tamamının çocuğu için TAT yöntemlerinden en az birini kullandı $\breve{g} l$, kullandı $\breve{g} \iota$ yöntemleri siklıkla kullandı̆̆ ve en fazla kullanılan yöntemin bitkisel tedavi olduğu tespit edilmiştir. Sağllk profesyonelleri, TAT yöntemlerinin etkinliği, dozajları, yan etkileri, toksisiteleri ve potansiyel ilaç etkileşimlerinden haberdar olmalıdır. Aileleri TAT kullanımı hususunda sorgulamalı, eğitim ve danışmanlık hizmeti sunmalıdır.

Anahtar kelimeler: Çocuk, geleneksel tıp, tamamlayıcı tedaviler

Çocuk Dergisi 2017; 17(4):174-181

Alındığı tarih: 14.10 .2017

Kabul tarihi: 31.10 .2017

*Milli Savunma Bakanlığ

**Antalya Atatürk Devlet Hastanesi

Yazıșma adresi: Dr. Duygu Akçay, Gülhane Loj. General Tevfik Sağlam Cad. Emrah Mah. Tokat Sok. Keskingil Apt. 60/B Blok No.26 Basınevler, Etlik / Ankara

e-posta: dakcay2010@hotmail.com

\author{
Use of Complementary and Alternative Therapy in Children \\ and Evaluation of Parental Information
}

Objective: In this research our aim was to evaluate the use of complementary and alternative therapies in children without chronic disease and the relevant knowledge of their parents.

Material and Method: The study was carried out as a descriptive type between 05.16.2016 and 05.27.2016. The universe of the study consisted of parents $(n=696)$ of children without a chronic illness who applied to the Department of Child Health and Diseases of Antalya State Hospital Hüseyin Savaș District Policlinic. Data were collected from a total of 125 parents volunteered to work within this group. In the collection of research data, a questionnaire consisting of descriptive characteristics of the families and questions about the research topic formulated by the investigators after screening relevant literature was used by the researchers.

Results: Most of (97.6\%) the interviewed parents were mothers and $63.2 \%$ of them were $35-44$ years old, while $51.2 \%$ of the families reported they had used complementary and alternative medicine (CAM) as a supportive treatment, and $38.4 \%$ of them used CAM for the relief of their children. All of the families stated that they had used at least one of the CAM types for their children and $72.8 \%$ of them had used these methods frequently. When using CAM, some (56\%) families had not observed any benefit or harm (97.6\%) for their children. It has been determined that the methods most known and used by the parents were herbal treatment and the religious methods, respectively. Families who indicated that they had medium and high income levels $(71.9 \%, 94.4 \%$, respectively) reported frequent use of CAM for their children. There was no statistically significant difference between parents' educational status, age range and use of CAM for their children.

Conclusions: It has been determined that all of our research group used at least one of the TAT methods and frequently for their children, and that the method they used most frequently was herbal treatment. Health professionals should be aware of the effectiveness, dosages, side effects, toxicity, and potential drug interactions of CAM methods. These families should be questioned on the use of CAM, and training and counseling should be offered on the use of CAM.

Keywords: Child, traditional medicine, complementary therapies

J Child 2017; 17(4):174-181

\section{GİRISS}

Yirminci yüzyılın ortalarından başlayarak, hastalıkların tanı ve tedavilerinde gözlenen hızlı gelişmeler tamamlayıcı ve alternatif tedavilerin kullanımında 
artışı da beraberinde getirmiştir. Tamamlayıcı tıp; modern tıbba yardımcı olarak kullanılan tedavi yöntemlerini tanımlarken, alternatif tıp; modern tıbbın yerini alan tedavi yöntemlerini içermektedir. Bu iki terim birlikte tamamlayıcı ve alternatif tıp (TAT) başlığg altında kullanılmaktadır ${ }^{(1)}$.

Günümüzde, yetişkinlerde TAT kullanımının artmas1 ile ilgili ilgi çekici veriler olsa da, çocuklarda yapılan çalışmalar daha sınırlı olmakla birlikte, TAT'ın çocuklarla kullanımı sıklıkla görülmektedir. Yurt dışında yapılan çalışma sonuçlarına göre, hastaneye yatırılmış çocukların yanı sıra ayaktan tedavi alanlarda TAT kullanımı \%1.8 ile \%84 arasında değişmektedir ${ }^{(2-5)}$. Avrupa ülkelerinde yapılan çalışmaları derleyen bir makalede, çocuklarda, son bir yıl içinde TAT kullanma \%56 olarak saptanmıştır ${ }^{(6)}$. Ülkemizde, yapılan çalışmalarda ise, çocuklarda TAT kullanma \%56,5 ile \%87 arasında değişmektedir (7-11). Tüm bu çalışmaların sonuçlarından da anlaş1labileceği gibi çocuklarda TAT kullanma durumu ülkemizde de genel olarak yüksektir. TAT kullanımının her yaşta sık olduğu ve kronik hastalıklarda bu sıklığın arttığı bilinmektedir ${ }^{(12,13)}$. Ülkemizde, TAT kullanımına dair çalışmalar, genellikle kronik hastalığı olan çocuklar üzerinde yapılmıştır ${ }^{(14-16)}$. Çocuklarda, bitkisel ilaçlar, homeopati, refleksoloji ve akupunktur en popüler tedaviler arasındadır ${ }^{(17,18)}$. Konvansiyonel tıptan duyulan rahatsızlık, memnuniyetsizlik, arkadaş, ailelerinden gelen olumlu geri bildirimler TAT kullanımı yaygınlığının nedenleri arasındadır ${ }^{(19,20)}$.

Kronik hastalığı olmayan çocuklarda da tamamlayıcı ve alternatif tıp yöntemleri oldukça sık uygulanmaktadır. Ancak yeterli sayı ve kalitede çalışma bulunmamaktadır ${ }^{(21)}$. Çocuklarda TAT yöntemlerin hakkında yüksek kalitede verilerin sağlanması, çocuk sağlığı ile ilgilen tüm sağlık profesyonellerinin, hastaları ve aileleri faydalı TAT yöntemleri hakkında bilgilendirmesini sağlayacaktır. Ebeveynlerin, eğitimcilerin ve sağlık personelinin bu konudaki duyarlılığını arttırması ve yapılacak diğer çalışmalara 1 şık tutması için bu araştırmada; kronik hastalığı olmayan çocuklarda tamamlayıcı ve alternatif tedavilerin kullanımı ve ebeveyn bilgilerinin değerlendirilmesi amaçlanmıştır.

\section{GEREÇ ve YÖNTEM}

Araştırma, 16.05.2016 ile 27.05.2016 tarihleri arasında tanımlayıcı tipte yapılmıştır. Antalya Atatürk Devlet Hastanesinden araştırmanın yürütülmesine ilişkin kurum izni ve araştırmaya katılan kişilerden yazılı onam formu alınarak araştırmaya başlanmıştır. Araştırmanın evrenini, Hüseyin Savaş Semt Polikliniği Çocuk Sağlığı ve Hastalıkları bölümüne başvuru yapan kronik bir hastalığı olmayan çocukların ebeveynleri ( $\mathrm{n}=696)$ oluşturmuştur. Bu grup içinde çalışmaya gönüllü olarak katılan toplam 125 ebeveynden konuya ilişkin veri toplanmıştır. Vakaları yaşları üç ay ile 16 yaş arasında değişen, üst ya da alt solunum yolu enfeksiyonu, idrar yolu enfeksiyonu, konstipasyon, diyare gibi gastrointestinal sistem hastalıklar nedeniyle başvuran çocuklar ile rutin kontrollerine gelen hastalar oluşturmuştur. Araştırma verilerinin toplanmasında konu ile ilgili literatür taranarak araştırmacılar tarafından oluşturulan, ailelerin tanımlayıcı özellikleri ve araştırma konusu ile ilgili sorulardan oluşan bir form kullanılmıştır.

Araştırmadan elde edilen veriler SPSS 15.00 programında değerlendirilmiştir. Araştırma grubunun, demografik bilgilerinin, araştırma konusu ile ilgili tanımlayıcı verilerin analizleri için frekans, yüzde alma teknikleri, çocuğu için TAT kullanım sıklığı ile bazı kategorik değişkenler arasındaki ilişkiyi test etmek için ise ki-kare uygulanmıştır. İstatistiksel olarak anlamlılık için 0,05 değeri kabul edilmiştir.

\section{BULGULAR}

Araştırma grubunun tanımlayıcı özellikleri Tablo 1'de verilmiştir. Araştırma sırasında görüşülen kişilerin \%97.6'sı anne (n=122) olup, \%63.2'si 35-44 yaş arasındadır. Ailelerin 88.8 'inin evli, \% 51.2'sinin üniversite mezunu ve $\% 88.8$ 'inin ekonomik durumlarının yüksek seviyede olduğu saptanmıştır. Ailelerin \%51.2'si destek, \%38.4'ü rahatlama amaçlı çocuğu için TAT kullandığını bildirmiştir. Ailelerin tamamı çocuğu için TAT yöntemlerinden en az birini kullandığını, kullandığı yöntemleri de \%72.8'i sıklıkla kullandığını ifade etmiştir. TAT kullanırken \%56'sının çocuğunda herhangi bir yarar, \%97.6'sının zarar gözlemlemediği belirlenmiştir. Araştırma grubunun \%60'1 TAT'1 kendisi araştırarak bilgi edinmiş ve \%47.2'si TAT ile ilgili danışmanlık hizmeti almak istemiştir (Tablo 1). 
Tablo 1. Araștırma grubunun tanımlayıcı özellikleri (n=125).

\begin{tabular}{|c|c|c|}
\hline & $\mathbf{n}$ & $\%$ \\
\hline \multicolumn{3}{|l|}{ Anketi dolduran kişi } \\
\hline Anne & 122 & 97.6 \\
\hline Baba & 3 & 2.4 \\
\hline \multicolumn{3}{|l|}{ Ebeveyn yaş aralığı } \\
\hline $16-24$ & 2 & 1.6 \\
\hline $25-34$ & 37 & 29.6 \\
\hline $35-44$ & 79 & 63.2 \\
\hline $45-54$ & 7 & 5.6 \\
\hline \multicolumn{3}{|l|}{ Medeni durum } \\
\hline Evli & 111 & 88.8 \\
\hline Boşanmış & 14 & 11.2 \\
\hline \multicolumn{3}{|l|}{ Öğrenim durumu } \\
\hline Temel eğitim & 34 & 27.2 \\
\hline Ortaöğretim & 27 & 21.6 \\
\hline Üniversite ve üstü & 64 & 51.2 \\
\hline \multicolumn{3}{|l|}{ Ekonomik durum } \\
\hline Düşük & 11 & 8.8 \\
\hline Orta & 96 & 76.8 \\
\hline Yüksek & 18 & 14.4 \\
\hline \multicolumn{3}{|l|}{ Çocuğu için TAT kullanım amacı* } \\
\hline Tedavi & 20 & 16 \\
\hline Destek & 64 & 51.2 \\
\hline Korunma & 25 & 20 \\
\hline Rahatlama & 48 & 38.4 \\
\hline \multicolumn{3}{|l|}{ Çocuğu için TAT kullanım sıklığı } \\
\hline Nadiren & 34 & 27.2 \\
\hline Siklıkla & 91 & 72.8 \\
\hline \multicolumn{3}{|c|}{$\begin{array}{l}\text { TAT kullanırken çocukta herhangi bir yarar } \\
\text { gözlemleme }\end{array}$} \\
\hline Evet & 55 & 44 \\
\hline Hayır & 70 & 56 \\
\hline \multicolumn{3}{|c|}{$\begin{array}{l}\text { TAT kullanırken çocukta herhangi bir zarar } \\
\text { gözlemleme }\end{array}$} \\
\hline Evet & 3 & 2.4 \\
\hline Hayır & 122 & 97.6 \\
\hline \multicolumn{3}{|l|}{ TAT öğrenme kaynağı } \\
\hline Merak ederek kendim araştırdım & 75 & 60 \\
\hline Arkadaşlarım tavsiye etti & 17 & 13.6 \\
\hline Ailem tavsiye etti & 12 & 9.6 \\
\hline Sağllk personeli tavsiye etti & 1 & 0.8 \\
\hline Diğer (televizyon. gazete. akraba vs.) & 20 & 16 \\
\hline \multicolumn{3}{|c|}{ TAT ile ilgili danışmanlık hizmeti almak isteme } \\
\hline Evet & 59 & 47.2 \\
\hline Hayır & 25 & 20 \\
\hline Kararsız & 41 & 32.8 \\
\hline
\end{tabular}

*Birden fazla seçenek işaretlenmiştir.

Katılımcıların TAT yöntemleri konusundaki bilgi düzeylerinin dağılımı Tablo 2'de gösterilmiştir. Ailelerin bitkisel tedavi (\%74.4), dini yöntem (\%64.8), diyet desteğini (\%52) genel olarak bilme düzeyleri diğer TAT yöntemlerine göre daha yüksek saptanmıştır. Aileler en az homeopatik (\%84), aleksandır teknigi (\%84), ayurveda (\%82.4) hakkında bilgi sahibi olduklarını bildirmişlerdir (Tablo 2). Ailelerin bitkisel tedavi (\%87.2), dini yöntem (\%66.4), diyet desteğini (\%44) kullanmaları diğer TAT yöntemlerine göre daha yüksek saptanmıştır (Tablo 3).
Katılımcıların çocuğu için TAT kullanım tercih nedenlerinin dağılımı Tablo 4'te gösterilmiştir. Çocukları için ailelerin; \%58.4'ünün tıbbi yöntemlere ek olarak fayda elde ettiği, \%52.8'inin çocuğunun TAT kullanımını daha kolay kabul ettiği, \%49.6'sının tıbbi tedavilerin yan etkilerinin daha çok olduğunu düşündüğü, \%48'inin TAT yöntemlerini tıbbi ilaçlardan daha doğal, az zehirli olduğunu düşündüğü ve TAT yöntemlerinin çoğunun çocuğunun canını acıtmadığı için TAT kullanmayı tercih ettikleri belirlenmiştir (Tablo 4).

Katılımcıların çocuğu için TAT kullanım sıklığı ile TAT kullanım amacı ve bazı sosyo-demografik değişkenlerin karşılaştırılması Tablo 5'te verilmiştir. Çocuğu için sıklıkla TAT kullanan ailelerin \%85.0'ının tedavi amaçlı kullandığı, \%70.5'inin kullanmadığı, \%84.0'ının korunma amaçlı kullandı ̆̆ı, \%70.0'inin kullanmadığı belirlenmiştir. Aralarındaki bu farklar istatistiksel olarak önemli saptanmamıştır ( $p>0.05$ ). Çocuğu için sıklıkla TAT kullanan ailelerin \%84.4'ünün destek amaçlı kullandığı, \%60.7'sinin kullanmadı $\breve{g} 1, \% 79.2$ 'sinin rahatlama amaçlı kullandı $\breve{g} 1, \% 62.5$ 'inin kullanmadığ 1 , aralarındaki bu farkların istatistiksel olarak önemli olduğu bulunmuştur (sirasiyla $\mathrm{p}<0.005 \mathrm{p}<0.05$ ), (Tablo 5).

Ekonomik durumlarını orta ve yüksek seviyede (sirasılyla \%71.9, \%94.4) olduğunu bildiren aileler çocuğu için sıklıkla TAT kullandığını bildirmiştir $(\mathrm{p}<0.05)$. Ebeveynlerin eğitim durumu ve yaş aralığ1 ile çocuğu için TAT kullanım sıklığ 1 arasında istatistiksel olarak bir fark bulunamamıştır ( $\mathrm{p}>0.05)$, (Tablo 5).

\section{TARTIŞMA}

Ailelerin tamamı çocuğu için TAT yöntemlerinden en az birini kullandığını, kullandığı yöntemleri de \%72.8'i sıklıkla kullandığını ifade etmiştir (Bkz. Tablo 1). TAT uygulamalarının çocuklarda kullanımı hakkındaki ülkemizde ve yurt dışında yapılan çalışmalar, genellikle kronik hastalığı olan çocuklara odaklanmıştır ${ }^{(6,12,13,14-16)}$. TAT kullanma Kanada'da, genel çocuk kliniğinde yapılmış kronik hastalığı olan bir grup hastayı da içeren bir çalışmada, $\% 56^{(20)}$, pediyatri acil servisinden örneklenen nüfus üzerinde yapılmış araştırmada ise \% 49 olarak bulunmuştur ${ }^{(22)}$. Amerikada \% $12^{(23)}$, Avrupa ülkelerinde $\% 56^{(6)}$ olarak 
Tablo 2. Katılımcıların TAT yöntemleri konusundaki bilgi düzeylerinin dağılımı.

\begin{tabular}{|c|c|c|c|c|c|c|c|c|}
\hline \multirow[b]{2}{*}{ Alternatif / tamamlayıcı tıp yöntemleri } & \multicolumn{2}{|c|}{$\begin{array}{c}\text { Hiç bilgim } \\
\text { yok }\end{array}$} & \multicolumn{2}{|c|}{$\begin{array}{l}\text { İsmini } \\
\text { duydum }\end{array}$} & \multicolumn{2}{|c|}{$\begin{array}{l}\text { Genel olarak } \\
\text { biliyorum }\end{array}$} & \multicolumn{2}{|c|}{$\begin{array}{c}\text { Tam olarak } \\
\text { biliyorum }\end{array}$} \\
\hline & $\mathbf{S}$ & $\%$ & $\mathbf{S}$ & $\%$ & $\mathbf{S}$ & $\%$ & $\mathbf{S}$ & $\%$ \\
\hline Akupunktur & 15 & 12 & 60 & 48 & 49 & 39.2 & 1 & 0.8 \\
\hline Aromaterapi & 41 & 32.8 & 55 & 44 & 29 & 23.2 & - & - \\
\hline Müzik terapisi & 22 & 17.6 & 73 & 58.4 & 30 & 24 & - & - \\
\hline Biyotedavi & 89 & 71.2 & 31 & 24.8 & 5 & 4 & - & - \\
\hline Ayurveda & 103 & 82.4 & 14 & 11.2 & 8 & 6.4 & - & - \\
\hline Dini yöntemler (Dua vb.) & 9 & 7.2 & 23 & 18.4 & 81 & 64.8 & 12 & 9.6 \\
\hline Bitkisel tedaviler & 6 & 4.8 & 24 & 19.2 & 93 & 74.4 & 2 & 1.6 \\
\hline Homeopatik & 105 & 84 & 16 & 12.8 & 4 & 3.2 & - & - \\
\hline Hipnoterapi & 77 & 61.6 & 28 & 22.4 & 20 & 16 & - & - \\
\hline Diyet desteği & 19 & 15.2 & 31 & 24.8 & 65 & 52 & 10 & 8 \\
\hline Refleksoloji & 51 & 40.8 & 49 & 39.2 & 25 & 20 & - & - \\
\hline Reiki & 45 & 36 & 51 & 40.8 & 24 & 19.2 & 5 & 4 \\
\hline Masaj & 16 & 12.8 & 46 & 36.8 & 54 & 43.2 & 9 & 7.2 \\
\hline Meditasyon/Gevşeme & 18 & 14.4 & 65 & 52 & 40 & 32 & 2 & 1.6 \\
\hline Renklerle terapi & 52 & 41.6 & 50 & 40 & 23 & 18.4 & - & - \\
\hline Yoga & 29 & 23.2 & 58 & 46.4 & 38 & 30.4 & - & - \\
\hline Aleksandır tekniği & 105 & 84 & 10 & 8 & 10 & 8 & - & - \\
\hline
\end{tabular}

*Birden fazla seçenek işaretlenmiştir.

Tablo 3. Katılımcıların çocukları için TAT yöntemlerini kullanma durumlarının dağılımı.

\begin{tabular}{|c|c|c|c|c|c|c|c|c|}
\hline \multirow[b]{2}{*}{ Alternatif / tamamlayıcı tıp yöntemleri } & \multicolumn{2}{|c|}{$\begin{array}{c}\text { Hiç } \\
\text { kullanmadım }\end{array}$} & \multicolumn{2}{|c|}{$\begin{array}{c}\text { 1-2 kez } \\
\text { kullandım }\end{array}$} & \multicolumn{2}{|c|}{$\begin{array}{c}\text { Bir Süre } \\
\text { kullandım }\end{array}$} & \multicolumn{2}{|c|}{$\begin{array}{c}\text { Düzenli } \\
\text { kullanırım }\end{array}$} \\
\hline & $\mathbf{s}$ & $\%$ & $\mathbf{S}$ & $\%$ & $\mathbf{S}$ & $\%$ & $\mathbf{S}$ & $\%$ \\
\hline Akupunktur & 123 & 98.4 & 2 & 1.6 & - & - & - & - \\
\hline Aromaterapi & 122 & 97.6 & 3 & 2.4 & - & - & - & - \\
\hline Müzik terapisi & 106 & 84.8 & 9 & 7.2 & 3 & 2.4 & 7 & 5.6 \\
\hline Biyotedavi & 124 & 99.2 & 1 & 0.8 & - & - & - & - \\
\hline Ayurveda & 125 & 100 & - & - & - & - & - & - \\
\hline Dini yöntemler (Dua vb.) & 42 & 33.6 & 36 & 28.8 & 24 & 19.2 & 23 & 18.4 \\
\hline Bitkisel tedaviler & 16 & 12.8 & 53 & 42.4 & 35 & 28 & 21 & 16.8 \\
\hline Homeopatik & 124 & 99.2 & 1 & 0.8 & - & - & - & - \\
\hline Hipnoterapi & 125 & 100 & - & - & - & - & - & - \\
\hline Diyet desteği & 70 & 56 & 29 & 23.2 & 20 & 16 & 6 & 4.8 \\
\hline Refleksoloji & 125 & 100 & - & - & - & - & - & - \\
\hline Reiki & 115 & 92 & 3 & 2.4 & 3 & 2.4 & 4 & 3.2 \\
\hline Masaj & 87 & 69.6 & 25 & 20 & 4 & 3.2 & 9 & 7.2 \\
\hline Meditasyon/Gevşeme & 109 & 87.2 & 10 & 8 & 6 & 4.8 & - & - \\
\hline Renklerle terapi & 123 & 98.4 & 2 & 1.6 & - & - & - & - \\
\hline Yoga & 123 & 98.4 & 2 & 1.6 & - & - & - & - \\
\hline Aleksandır tekniğgi & 125 & 100 & - & - & - & - & - & - \\
\hline
\end{tabular}

*Birden fazla seçenek işaretlenmiştir.

bulunmuştur. Ülkemizde düşük gelir düzeyine sahip ailelerin çocuklarına TAT uygulamalarını belirlemek amacıyla İzmir'de yapılmış çalışmada $\% 75,8^{\left({ }^{(8)}\right.}$, yalnızca \%6'sında süreğen bir hastalık olan çocuklar üzerinde Ankara'da yapılmış olan çalışma da ise $\% 87{ }^{(9)}$ olarak saptanmıştır. Taşar ve ark.'nın ${ }^{(9)}$ yaptı ̆̆ çalışmada, ailelerin $\% 50.5$ 'i haftada birden az, $\% 30$ 'u hastalandıkça; \%17'si sık, \%2.5'i her gün çocukları için TAT kullandıklarını belirtmişlerdir. Giray Bozkaya ve ark.'nın ${ }^{(8)}$ çalışmasında ebeveyn- lerin, \%75,8'inin TAT'1 daha önce bir ya da birkaç kez kullandıkları saptanmıştır. İzmir'de yapılmış başka bir çalışmada, çocuklarda TAT kullanma $\% 56,5^{(7)}$, Gaziantep'te yapılmış bir çalışmada ise $\% 58,6$ olarak bulunmuştur ${ }^{(10)}$. Tuncel ve ark. ${ }^{(1)}$ kronik hastalığı olmayan çocuklarda TAT kullanımı $\% 83$ olarak bulmuşlardır. Bu çalışmaların sonuçlarında olduğu gibi bizim çalışmamızda da aileler çocuklarında yüksek oranda ve sıklıkta TAT kullanmaktadırlar. 
Tablo 4. Katılımcıların çocuğu için TAT kullanım tercih nedenlerinin dağılımı.

\begin{tabular}{|c|c|c|c|c|c|c|}
\hline \multirow[b]{2}{*}{ TAT kullanımı tercih nedenleri } & \multicolumn{2}{|c|}{ Katılmıyorum } & \multicolumn{2}{|c|}{ Kararsızım } & \multicolumn{2}{|c|}{ Katılıyorum } \\
\hline & $\mathbf{s}$ & $\%$ & $\mathbf{s}$ & $\%$ & $\mathbf{s}$ & $\%$ \\
\hline TAT yöntemi kullanarak tıbbi yöntemlere ek olarak fayda elde edeceğime inanıyorum. & 20 & 16 & 32 & 25.6 & 73 & 58.4 \\
\hline Çocuğum bu tür tedaviyi daha kolay kabul ediyor. & 17 & 13.6 & 42 & 33.6 & 66 & 52.8 \\
\hline Tıbbi tedavilerin yan etkilerinin daha çok olduğunu düşünüyorum. & 24 & 19.2 & 39 & 31.2 & 62 & 49.6 \\
\hline TAT yöntemlerinin tıbbi ilaçlardan daha doğal ve az zehirli olduğunu düşünüyorum. & 30 & 24 & 35 & 28 & 60 & 48 \\
\hline TAT şekillerinin çoğu çocuğumun canını acıtmıyor. & 30 & 24 & 35 & 28 & 60 & 48 \\
\hline TAT’’n hastalığın ilerlemesini önleyeceğini ve yararına inanıyorum. & 25 & 20 & 44 & 35.2 & 56 & 44.8 \\
\hline Çocuğum için TAT yöntemlerini kullandığımda kendimi daha iyi hissediyorum. & 21 & 16.8 & 49 & 39.2 & 55 & 44 \\
\hline Çocuğumun tedavisinde etkin olduğunu düşünüyorum. & 25 & 20 & 56 & 44.8 & 44 & 35.2 \\
\hline TAT yöntemlerinin etkin ve güvenilir olduğunu düşünüyorum. & 19 & 15.2 & 67 & 53.6 & 39 & 31.2 \\
\hline
\end{tabular}

Tablo 5. Katılımcıların çocuğu için TAT kullanım sıklığı ile TAT kullanım amacı ve bazı sosyo-demografik değişkenlerin karşılaştırılması.

\begin{tabular}{|c|c|c|c|c|c|c|}
\hline \multirow[b]{3}{*}{ TAT kullanım amacı } & \multicolumn{4}{|c|}{ Çocuğu için TAT kullanım sıklığı } & \multirow{3}{*}{$\begin{array}{c}\text { Toplam } \\
\mathbf{S}\end{array}$} & \multirow{3}{*}{ Önemlilik } \\
\hline & \multicolumn{2}{|c|}{ Nadiren } & \multicolumn{2}{|c|}{ Sıklıkla } & & \\
\hline & $\mathbf{s}$ & $\%$ & $\mathbf{s}$ & $\%$ & & \\
\hline \multicolumn{7}{|l|}{ Tedavi } \\
\hline Hayır & 31 & 29.5 & 74 & 70.5 & 105 & 0.181 \\
\hline Evet & 3 & 15 & 17 & 85 & 20 & \\
\hline \multicolumn{7}{|l|}{ Destek } \\
\hline Hayır & 24 & 39.3 & 37 & 60.7 & 61 & 0.003 \\
\hline Evet & 10 & 15.6 & 54 & 84.4 & 64 & \\
\hline \multicolumn{7}{|l|}{ Korunma } \\
\hline Hayır & 30 & 30 & 70 & 70 & 100 & 0.159 \\
\hline Evet & 4 & 16 & 21 & 84 & 25 & \\
\hline \multicolumn{7}{|l|}{ Rahatlama } \\
\hline Hayır & 16 & 20.8 & 61 & 79.2 & 77 & 0.041 \\
\hline Evet & 18 & 37.5 & 30 & 62.5 & 48 & \\
\hline \multicolumn{7}{|l|}{ Ekonomik Durum } \\
\hline Düşük & 6 & 54.5 & 5 & 45.5 & 11 & 0.011 \\
\hline Orta & 27 & 28.1 & 69 & 71.9 & 96 & \\
\hline Yüksek & 1 & 5.6 & 17 & 94.4 & 18 & \\
\hline \multicolumn{7}{|l|}{ Öğrenim Durumu } \\
\hline Temel eğitim & 6 & 17.6 & 28 & 82.4 & 34 & 0.337 \\
\hline Ortaöğretim & 8 & 29.6 & 19 & 70.4 & 27 & \\
\hline Üniversite ve üstü & 20 & 31.3 & 44 & 68.8 & 64 & \\
\hline
\end{tabular}

*Ki-kare testi

Çalışmamızda, ailelerin TAT kullanırken yarısından fazlası çocuğunda herhangi bir yarar, tamamına yakını herhangi bir zarar da gözlemlemediğini bildirmiştir (Bknz. Tablo 1). Taşar ve ark.'nın ${ }^{(9)}$ yaptı ğı çalışmada, aileler çocuğu için uyguladığı TAT yöntemlerinden yalnızca \%1'inde zararlı etkileri olduğunu, \%77'sinde yararlı olduğunu belirtmiştir. Yapılan başka bir çalışmada çocuğu için uyguladığı TAT yöntemlerinden ailelerin \%10.6's1 zarar, \%80.9'1 yarar gördüğünü bildirmiştir ${ }^{(8)}$. Araz ve Bülbül ${ }^{(10)}$ yaptı̆̆ çalışmasında, aileler \%57.7 oranında kullandıkları yöntemi "biraz" yararlı, \%18.6 oranında yöntemin "oldukça" yararlı bulmuşlardır. Karaciğer ve böbrek fonksiyonları iyi gelişmemiş olan çocuklarda TAT uygulamalarının zararlı yan etkilere olabilmekte ${ }^{(24)}$ ve tıbbi tedaviyi geciktirme ve birakma gibi dolaylı yan etkileri de görülebilmektedir ${ }^{25)}$. Doğal olmaları nedeniyle güvenli tedavi yöntemleri olarak bilindikleri ve pazarlandıkları için TAT uygulamalarının yan etkileri, zararlı etkileri olabileceği sıklıkla göz ardı 
edilmektedir. Sağlık profeyonelleri, TAT yöntemlerinin etkinliği, dozajları, yan etkileri, toksisiteleri ve potansiyel ilaç etkileşimlerinden haberdar olmalıdır. Sağlık profeyonelleri, ebeveynlere rutin olarak TAT kullanımını sormalı ve kullanım nedenlerini ile beklenen sonuçlarını tartışmalıdırlar. Sağlık profesyonelleri, bu tür bir tartışma vasitasıyla, ebeveynlerin tercihlerine yardımcı olabilirler.

Araştırma grubunun yarıdan fazlası TAT'1 kendisi araştırarak bilgi edinmiş ve \%47.2'si TAT ile ilgili danışmanlık hizmeti almak istemiştir (Bknz. Tablo 1). Önceki yıllarda yapılan araştırmalarda TAT uygulamaları hakkında en çok aile büyüklerinden bilgi alındığı görülmektedir ${ }^{(7,9,11,20)}$. Çalışmamızda kendisi araştırarak bilgi edinen ailelerin oranının fazla olmasının nedeni araştırma grubunun öğrenim seviyesinin (\%51.1'inin üniversite ve üstü) yüksek olması olabilir. Araştırma grubunun yarıya yakınının danışmanlık hizmeti almak istemesi sağlık çalışanlarına olumlu bir mesaj vermektedir. Hizmet verilen gruba bu konuda eğitim ve danışmanlık hizmeti sunulması durumunda katılımın yükssek olacağı değerlendirilmektedir.

Çalışmamızda ailelerin en fazla bildiği ve kullandığı yöntemlerin sırasıyla bitkisel tedavi ile dini yöntem olduğu saptanmıştır (Bknz Tablo 2 ve 3). Tuncel ve ark.'nın ${ }^{(11)}$ çalışmasında katılımcıların çocuklarının $\% 73$ 'ünde inanıs temelli uygulamaları, \%57'sinde bitkisel yöntemleri kullandığı saptanmıştır. Araz ve Bülbül ${ }^{(10)}$ ile Öztürk ve Karayağız'ın ${ }^{(7)}$ çalışmasında aileler en çok bitkisel yöntemleri (sırasıyla \%82.7, \%77) kullandığını bildirmiştir. Taşar ve ark.'nın (9) çalışmasında, en sık kullanılan TAT çeşidi bitki çayları (\%31) ve zeytin/badem yağ 1 içirme (\%28) olarak belirlenmiştir. Giray Bozkaya ve ark.'nın ${ }^{(8)}$ çalışmasında ailelerin kullandıkları TAT yöntemleri arasında şifalı bitkiler, tuzlama ve "dua" ilk sıralarda yer almaktaydı. Çalışmamız diğer çalışma sonuçlarını desteklemektedir. Bitkilerin sağ lığı korumak ya da geri kazanmak için, bütün toplumlar tarafından tarihin her döneminde kullanılmıştır ${ }^{(26)}$. Son yıllarda sentetik ilaçlarla meydana gelebilen ciddi yan etkilerin yol açtığı medikal ve ekonomik sorunlar gibi birçok faktöre bağlı olarak bitkisel tedavi yeniden popüler hâle gelmiştir ${ }^{(27)}$. Günümüzde bitkisel ürünlerin yan etkilerin olabileceği yanı sıra tıbbi tedaviyi geciktirme, bırakma gibi etkilerinin de olabileceği bilinmektedir ${ }^{(25)}$. Bitkiler; botanik açıdan tayini yapılmış, mikrobiyolojik ve kimyasal kontrollü, etken madde miktarı belli, standardize edilmiş ve hijyenik şartlarda ambalajlanmış olarak hastaya sunulması gerekir ${ }^{(28)}$. Sağlık profesyonelleri bu konuda ailelere eğitim ve danışmanlık hizmeti vermelidir. Duanın, kişinin ağrılarını azalttığı, depresyon ve anksiyete durumlarında kişiyi rahatlattığı bildirilmiştir ${ }^{(29)}$. Dua uygulamasının bireye zarar verici herhangi bir yan etkisi olmadığından ve rahatlama sağladığından hastalar ve yakınları bu konuda desteklenebilir.

Çalışmamızda aileler çocukları için TAT kullanma tercihleri arasında, tıbbi yöntemlere ek olarak fayda elde etme, çocuğunun bu yöntemleri daha kolay kabullenmesi ve tıbbı tedavilerin yan etkilerinin daha çok olma nedenlerini üst sırada belirtmişlerdir (Bknz. Tablo 4). Yapılan bir çalışmada TAT kullanan ebeveynlerin tıbbi tedavilerden memnuniyet düzeylerinin daha düşük olduğu saptanmıştır ${ }^{(20)}$. Ayrıca tıbbi tedavilerin yan etkilerinden korkma, umutsuzluk, tinsel boyutunun olması, kolay kabul görmesi, girişim gerektirmemesi, kolayca erişilebilmesi ve ebeveynin güvenilir olduğunu düşünmesi nedenleri ile kullandıkları saptanmıştır ${ }^{(30,31)}$. Yapılan başka bir çalışmada, aileler aylık kazançtan bağımsız olarak TAT uygulamalarını sıklıkla kolay ulaşılabilir olmaları nedeniyle seçtikleri belirlenmiştir ${ }^{(8)}$. Araştırma grubumuzun tercih nedenleri arasında üst siralarda bildirdikleri nedenler diğer çalışma bulguları ile benzerlik göstermektedir. Sağlık profeyonelleri, ailelere TAT yöntemlerinin de yan etkileri olduğu ve çocuğu bu yöntemleri kolay kabul ediyor diye geri dönüşümü mümkün olmayan sonuçlarla karşı karşıya kalabilecekleri hususunda uyarıda bulunmalılardır.

Öztürk ve Karayağız'ın ${ }^{(7)}$ çalışmasında olduğu gibi bizim çalışmamızda da aileler destek ve rahatlama amaçlı çocuğu için TAT kullandığını bildirmiştir (Bknz. Tablo 1, 5). Destek ve rahatlama amaciyla kullanan ailelerin sıklıkla TAT kullandıkları belirlenmiştir (Bknz. Tablo 5).. Araştırma grubumuzun bu tür uygulamaları tamamlayıcı olarak kullanmayı tercih ettiğini söylemek yanlış olmayacaktır. Bu nedenle, ailelerin tedavi ve korunma amaçlı TAT kullanım oranlarının ve sıklığının az olması olumlu bir sonuç olarak değerlendirilmektedir.

Ekonomik durumlarını orta ve yüksek seviyede (sıra- 
sıyla \% 71.9, \%94.4) olduğunu bildiren aileler çocuğu için sıklıkla TAT kullandığını bildirmiştir (Bknz. Tablo 5). Literatürde çocuğu için TAT kullanımının gelir düzeyi yüksek olanlarda daha sık olduğunu bildiren yayınlar bulunduğu gibi gelir düzeyi ile ilişkili olmadığını gösteren yayınlarda mevcuttur ${ }^{(10,11,20,23,32)}$. Yapılacak eğitim ve müdahalelerde eğitim seviyesi yüksek olan gruplara öncelik verilmelidir. Giray Bozkaya ve ark. ${ }^{(8)}$ ve Tuncel ve ark.'nın ${ }^{(11)}$ çalışmalarında olduğu gibi bizim çalışmamızda da ebeveynlerin öğrenim durumu, yaş aralığı ile çocuğu için TAT kullanım sıklığı arasında istatistiksel olarak bir fark bulunamamıştır (Tablo 5). Bu sonuç, araştırma grubunun TAT kullanım sıklığının, ailenin yaş ve eğitim durumundan bağımsız olduğunu düşündürmektedir.

\section{SONUÇ ve ÖNERILLER}

Sonuç olarak, araştırma grubumuzun tamamının çocuğu için TAT yöntemlerinden en az birini kullandı $\breve{g} 1$, kullandığ $\breve{y}_{1}$ yontemleri sıklıkla kullandı $\breve{g}_{1}$ ve en fazla bildiği, kullandığı yöntemin bitkisel tedavi olduğu belirlenmiştir. Ailelerin destek ve rahatlama amaçlı çocuğu için TAT kullanmayı tercih ettiği saptanmıştır. Sağlık profesyonellerinin, bu yöntemler hakkında yeterli bilgiye sahip olmaları, bu yöntemleri olası riskleri, yararları ve kısıtlamaları gibi konularda hastaları tam olarak bilgilendirmeleri ve rehberlik etmeleri, hastalardan gelen sorulara açık ve net bir şekilde yanıt verebilmeleri çok önemlidir. Sağlık profesyonelleri, öncelikle ailelerin en çok kullandığ 1 yöntem olan bitkisel tedavi yöntemi konusunda ailelere sorular sormalı, eğitim ve danışmanlık hizmeti sunmalıdır. Ülkemizde kronik hastalığı olmayan çocukların TAT kullanımını araştıran çalışma sayısı azdır. Bu konuyla ilgilenen araştırmacıların; çalışmalarını örneklem grubunu genişleterek yapmaları önerilmektedir.

\section{KAYNAKLAR}

1. NIH Panel on Definition and Description. Defining and describing complementary and alternative medicine. Alternat Ther Health Med 1997;3:49-57.

2. Davis MP, Darden PM. Use of complementary and alternative medicine by children in the United States. Arch Pediatr Adolesc Med 2003;157:393-6. https://doi.org/10.1001/archpedi.157.4.393

3. Hanson E, Kalish LA, Bunce E, Curtis C, McDaniel $\mathbf{S}$,Ware J, et al. Use of complementary and alternative medicine among children diagnosed with autism spectrum disorder. J Autism Dev Disord 2007;37:628-36. https://doi.org/10.1007/s10803-006-0192-0

4. Lim A, Cranswick N, Skull S, South M. Survey of complementary and alternative medicine use at a tertiary children's hospital. J Paediatr Child Health 2005;41:424-7. https://doi.org/10.1111/j.1440-1754.2005.00659.x

5. Kelly KM, Jacobson JS, Kennedy DD, Braudt SM, Mallick M, Weiner MA. Use of unconventional therapies by children with cancer at an urban medical center. J Pediatr Hematol Oncol 2000;22:412-6. https://doi.org/10.1097/00043426-200009000-00005

6. Zuzak TJ, Boňková J, Careddu D, Garami M, Hadjipanayis A, Jazbec J. et al. Use of complementary and alternative medicine by children in Europe: published data and expert perspectives. Complement Ther Med 2013;21:S34-47.

https://doi.org/10.1016/j.ctim.2012.01.001

7. Özturk C, Karayağız G. Exploration of the use of complementary and alternative medicine among Turkish children. J Clin Nurs 2008;17:2558-64. https://doi.org/10.1111/j.1365-2702.2008.02329.x

8. Giray Bozkaya Ö, Akgün İ, Birgi E, Çinkoğlu A, Gög K, Karadeniz D. Anne babaların çocuklarında uyguladıkları alternatif tıp yöntemleri. DEÜ Tip Fakültesi Dergisi 2008;22:129-35.

9. Taşar MA, Potur ED, Kara N, Bostancı İ, Dallar Y. Düşük gelir düzeyine sahip ailelerin çocuklarına tamamlayıcı veya alternatif tıp uygulamaları: Ankara hastanesi verileri. Türkiye Çocuk Hast Derg 2011;5: 81-8.

10. Araz N, Bulbul S. Use of complementary and alternative medicine in a pediatric population in southern Turkey. Clin Invest Med 2011;34:E21-9. https://doi.org/10.25011/cim.v34i1.14909

11. Tuncel T, Şen V, Kelekçi S, Karabel M, Şahin C, Uluca Ü, et al. Kronik hastalığı olmayan çocuklarda tamamlayıcı ve alternatif tıp kullanımı. Türk Ped Ars 2014;49:148-53. https://doi.org/10.5152/tpa.2014.1498

12. Snyder J, Brown P. Complementary and alternative medicine in children: an analysis of the recent literature. Curr Opin Pediatr 2012;24:539-46. https://doi.org/10.1097/MOP.0b013e328355a214

13. Gottschling S, Gronwald B, Schmitt S, Schmitt C, Längler A, Leidig E, et al. Use of complementary and alternative medicine in healthy children and children with chronic medical conditions in Germany. Complement Ther Med 2013;21:S61-9. https://doi.org/10.1016/j.ctim.2011.06.001

14. Babayigit A, Olmez D, Karaman O, Uzuner N. Complementary and alternative medicine use in Turkish children with bronchial asthma. J Altern Complement Med 2008;14:797-9. https://doi.org/10.1089/acm.2008.0172

15. Muslu GK, Öztürk C. Tamamlayıcı ve alternatif tedaviler ve çocuklarda kullanımı. Cocuk Sag Hast Derg 2008;51:62-6.

16. Orhan F, Sekerel BE, Kocabaş CN, Saçkesen C, Adalıoğlu G, Tuncer A. Complementary and alternative medicine in children with asthma. Ann Allergy Asthma Immunol 2003;90:611-5. https://doi.org/10.1016/S1081-1206(10)61864-9

17. Gottschling S, Reindl TK, Meyer S, Berrang J, Henze G, Graeber S, et al. Acupuncture to alleviate 
chemotherapy-induced nausea and vomiting in pediatric oncology - a randomized multicenter crossover pilot trial. Klin Padiatr 2008;220(6):365-70. https://doi.org/10.1055/s-0028-1086039

18. Gottschling S, Meyer S, Gribova I, Distler L, Berrang J, Gortner L, et al. Laser acupuncture in children with headache: a double-blind, randomized, bicenter, placebo controlled trial. Pain 2008;137(2): 405-12. https://doi.org/10.1016/j.pain.2007.10.004

19. Robinson N, Blair M, Lorenc A, Gully N, Fox, P, Mitchell K. Complementary medicine use in multiethnic paediatric outpatients. Complement Ther Clin Pract 2008;14:17-24. https://doi.org/10.1016/j.ctcp.2007.07.003

20. Jean D, Cyr C. Use of complementary and alternative medicine in a general pediatric clinic. Pediatrics 2007;120:e138-41. https://doi.org/10.1542/peds.2006-3105

21. Meyer S, Gortner L, Larsen A, Kutschke G, Gottschling S, Gräber S, et al. Complementary and alternative medicine in paediatrics: a systematic overview/synthesis of Cochrane Collaboration reviews. Swiss Med Wkly 2013;143:w13794 https://doi.org/10.4414/smw.2013.13794

22. Goldman RD, Vohra S. Complementary and alternative medicine use by children visiting a pediatric emergency department. Can J Clin Pharmacol 2004;11: e247.

23. Barnes PM, Bloom B, Nahin RL. Complementary and alternative medicine use among adults and children: United States, 2007. 2008 Hyattsville, MD: National Center for Health Statistics; National health statistics reports. Available from: http://www.cdc.gov/ nchs/data/nhsr/nhsr012.pdf.
24. Muslu Karayağız G, Öztürk C. Tamamlayıcı ve alternatif tedaviler ve çocuklarda kullanımı. Cocuk Sag Hast Derg 2008;51(1):62-7.

25. Cohen NM, Kemper K. Complementary therapies in pediatrics: a legal perspective. Pediatrics 2005;115(3): 774-80. https://doi.org/10.1542/peds.2004-1093

26. Sarısen Ö, Çalıskan D. Fitoterapi: Bitkilerle tedaviye dikkat. Sted 2005;14:182-8.

27. Vickers A, Zollman C. ABC of complementary medicine-herbal medicine. BMJ 1999;319:1050-3. https://doi.org/10.1136/bmj.319.7216.1050

28. Özbek H. Cinsel ve jinekolojik sorunların tedavisinde bitkilerin kullanımı. Van Tip Dergisi 2005;12:170-4.

29. Bardia A, Barton DL, Prokop LJ, Bauer BA, Moynihan TJ. Efficacy of Complementary and alternative medicine therapies in relieving cancer pain: A Systematic Review. J Clin Oncol 2006;24(34):545764.

https://doi.org/10.1200/JCO.2006.08.3725

30. Ernst E. The role of complementary and alternative medicine. BMJ 2000;321(7269):1133-5. https://doi.org/10.1136/bmj.321.7269.1133

31. Kurt E, Bavbek S, Pasaoglu G, Abadoglu O, Misirligil Z. Use of alternative medicines by allergic patients in Turkey. Allergol Immunopathol (Madr) 2004;32(5):289-94. https://doi.org/10.1016/S0301-0546(04)79257-5

32. Birdee GS, Phillips, RS, Davis, RB, Gardiner P. Factors associated with pediatric use of complementary and alternative medicine. Pediatrics 2010;125:249-56. https://doi.org/10.1542/peds.2009-1406 